\title{
How does practice improve the skills of medical students during consecutive training courses? ${ }^{1}$
}

\author{
Erzsebet Vanyolos', Istvan Furka", Iren Miko"', Aida Viszlai"v, Norbert Nemethv, Katalin Peto ${ }^{\mathrm{vI}}$
}

\begin{abstract}
'MSc, Head Nurse, Department of Operative Techniques and Surgical Research, Institute of Surgery, Faculty of Medicine, University of Debrecen, Hungary. Acquisition, analysis and interpretation of data; manuscript preparation.

"PhD, DSc, Emeritus Professor, Department of Operative Techniques and Surgical Research, Institute of Surgery, Faculty of Medicine, University of Debrecen, Hungary. Scientific and intellectual content of the study, conception and design of the study, critical revision.

I'PhD, Full Professor, Department of Operative Techniques and Surgical Research, Institute of Surgery, Faculty of Medicine, University of Debrecen, Hungary. Scientific and intellectual content of the study, conception and design of the study.

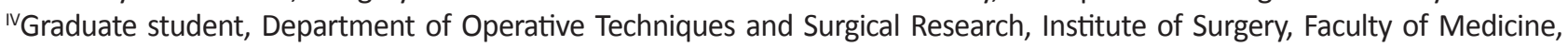
University of Debrecen, Hungary. Acquisition and analysis of data, manuscript preparation.

'PhD, Associate Professor, Head, Department of Operative Techniques and Surgical Research, Institute of Surgery, Faculty of Medicine, University of Debrecen, Hungary. Scientific and intellectual content of the study, conception and design of the study, analysis of data, critical revision, final approval.

VIPhD, Assistant Professor, Department of Operative Techniques and Surgical Research, Institute of Surgery, Faculty of Medicine, University of Debrecen, Hungary. Scientific and intellectual content of the study, conception and design of the study, analysis of data, critical revision, final approval.
\end{abstract}

\section{Abstract}

Purpose: To follow-up the development of medical students in taking a stitch using two different bench models, and to assess their performance with regards to gender, handedness, prior recreational activities and interest in surgery.

Methods: The study was performed during the compulsory basic $(n=152)$ and the consecutive elective course $(n=27)$. Students took simple interrupted stitches into synthetic and biopreprate models in the classroom and in the operating room. The time needed for that was measured and the quality was scored, using an OSATS (Objective Structured Assessment of Technical Skill) checklist that had been adapted to our training programs.

Results: Students' performance improved both in time and quality during classes, over the course and compared basic to the elective course, too. No significant difference was found in relation to gender and handedness but certain recreational activities and special interest in surgery led to better results. Operating room environment had a slight negative effect on students' performance.

Conclusion: The study could provide objective skill assessment, monitoring has revealed deficiencies and influencing factors. Objective feedback, valid and reliable assessment is important in teaching surgical skills. In addition it may contribute to higher surgical safety later on in the clinical practice.

Key words: Education, Medical. Training Courses. Suture Techniques. 


\section{Introduction}

A number of skills are required to achieve high standards in surgery, including quantifiable ones, such as sound base of knowledge, mastery of decision-making, good communication skills, and those, that are more difficult to assess, such as practical technique and dexterity. Such skills can only be achieved by teaching and experience ${ }^{1}$.

Surgical training is undergoing a paradigm shift, based on technological advances in health care. The traditional model of acquisition of surgical skills in the operating room on patients is no longer acceptable. Unfortunately, it is difficult to gain experience without real-life situations, but there are ethical concerns to practice new skills on patients at any level of training ${ }^{2-6}$. Simulation in surgical training has recently gained an important role. The new approach is based on low-fidelity bench models, living and non-living animal models (biopreparates, biomodels), virtual reality high-fidelity models and human performance simulators ${ }^{2-6}$. The key point is that students can acquire the necessary practical knowledge under safe conditions, without risk, with the advantages of decreased stress and the ability to tolerate and correct performance errors ${ }^{7}$.

With the tightening of animal protection legislation, it is increasingly difficult to justify the use of living animal models. Furthermore, the practice in live animals and human cadavers is associated with risking the patient of infections, need for specialized facilities and ethical and legal issues ${ }^{8}$. So bench models (inanimate models, i.e. porcine leg, chicken leg, synthetic professional plastic skin pad) play an increasing role, since they can sufficiently replace certain interventions in living tissue.

One of the most important criteria of a model is to develop the relevant expertise and skills (e.g., incision techniques, suturing).
Furthermore, it has to be effectively applicable, standardized and reproducible to test the specific process before performing it on living tissue. As a result, the training period will be shorter, the education more efficient, the performance of the intervention better. After all, mastery of practical skills is beneficial both to the future doctors and their patients. Although plastic training models are far from reality, they have several advantages, such as low cost, portability, possibility of unsupervised use and recyclability, which enables unlimited amount of practice9. There are also cadaveric animal models, so called 'biomodels' available that are closer to reality. The use of them provides opportunity to learn, practice and refine in situ preparative jobs, techniques and movements ${ }^{7,10-15}$. In our teaching program plastic and biomodels are used during "Basic Surgical Techniques" education and during the consecutive elective courses for teaching suturing and knotting techniques ${ }^{16-18}$.

For the safety of patients proper suturing technique is essential, therefore sound teaching of the technique is of crucial importance in surgery. The quality of the stitch is a key factor. Suture material, needle, needle holder and the surgeon together form a dynamic unit and if any 'component' does not function properly, the result is inadequate and the surgical safety is impaired. Tools or instruments can be characterised by objective parameters, while the surgeon can only be evaluated by the result of his activity. In the process the errors and defects can be observed and eliminated that contributes to better surgical safety. However, it is difficult to be objective. With our work we wanted to provide data concerning similar analyses.

During the study we followed up the development of undergraduate medical students in taking a stitch in two different type of models (synthetic and biomodel), at two different venues (classroom and operating 
room), during the basic and the consecutive advanced elective course. We also tried to find any difference in their performance with regards to gender, handedness, prior recreational activities and special interest in surgery.

\section{- Methods}

\section{Education program and participants}

The measurements were carried out during the "Basic Surgical Techniques" compulsory subject for 3rd year medical students (Survey 1) and the "Surgical Operative Techniques" consecutive compulsory chosen elective course for $3 \mathrm{rd}$ and 4 th year medical students (Survey 2) of the undergraduate medical education, at the Department of Operative Techniques and Surgical Research of the Institute of Surgery, Faculty of Medicine, University of Debrecen.

During "Basic Surgical Techniques" course students are expected to acquire basic knowledge in surgical skill, among others basic suturing and knotting techniques, while "Surgical Operative Techniques" course is announced for students who have completed the basic course and are particularly interested in surgery ${ }^{16,19}$.

In the first survey 152 (58 males, 94 female), in the second survey 27 out of the 152 (11 males, 16 female) volunteer medical students participated. In Survey 2 only those students took part who registered for the elective course as they were interested in surgery.

Before the survey the participants filled a questionnaire on gender, dominant hand, specific interest in manual professions, hobbies that presume better manual skills or have a potential positive effect on it (e.g., playing musical instruments, craftwork: handcraft, fine arts, computer games).

\section{The task and the applied models}

Prior to the test the students got the necessary theoretical knowledge and received detailed practical demonstration by the tutors. They took simple interrupted stitches, depending on the schedule of the classes either into 3-layer professional synthetic skin pad (Limbs \& Things Ltd, UK) or into porcine biopreparate models (e.g., porcine foot) with the assistance of another student, whose role was to hold the end of the thread and pass the scissors in time to cut the thread after tying the knot. The necessary instruments (surgical forceps and Mathieu needle-holder with suitable needle and thread) were chosen and prepared by the student her/himself.

The time to take a stitch into the model and to fix it with two-handed surgical knot was measured by digital chronometer. The measurement started from the moment the tip of the needle touched the model, through taking the stitch and tying the knot to the moment the thread had been cut. Polyesther thread (Tervalon, CHIRANA T. Injecta, s.r.o, Czech Republic) was used, 2-0 for the biomodel and 3-0 for the plastic model.

The synthetic model was a $125 \times 72 \mathrm{~mm}$ 3-layer synthetic professional skin pad with a similar drag and strength to human skin and comprising epidermis, dermis and subdermal layer, fixed into a flexible plastic jig (Limbs \& Things Ltd, UK). The ex vivo animal or so-called biopreparate model (briefly biomodel) was porcine foot, purchased and used with the authorization of the competent authority.

\section{Skill assessment methods}

The plastic model measurements of the basic course were carried out in the 5th week of the course, in the classroom (synthetic model in the classroom, S-CR) and in the 8th 
week, in the operating room (synthetic model in the operating room, S-OR). The elective course measurements were performed in the $1^{\text {st }}$ week of the course in the classroom (S-CR) and in the $3^{\text {rd }}$ week in the operating room (S-OR). The biomodel (porcine foot) measurements were performed in the $4^{\text {th }}$ and $14^{\text {th }}$ week of the basic and in the $2^{\text {nd }}$ and $4^{\text {th }}$ week of the elective course, each time in the operating room (biomodels in operating room B-OR I, B-OR II). Students had the opportunity to practice suturing week by week, several times.

The classroom measurements were carried out sitting at a table, without gloves, wearing casual clothes, while during the operating room measurements the students were standing at the operative table, wearing operating room clothing (surgical gown, mask and gloves).

On each occasion there were 2 testing modules at the beginning and at the end of the class. The improvement was checked by comparison of the two values. In the meantime, the students could train themselves by taking more stitches. For further analyzation the average values of the initial and final measurements were used.

To assess the quality of the performance a modified OSATS (Objective Structured Assessment of Technical Skill) taskspecific checklist was used without the global rating scale. Similar to the checklist of Reznick and a modified version by Boros et al. ${ }^{6,22}$ our modification comprised a series of yes/no items with a maximum score of 20. An experienced tutor evaluated the implementation.

According to the time required for the sutures the students were divided into 3 categories based on the quartiles: belowaverage (lower quartile $<25 \%$ ), average (interquartile range $25-75 \%$ ) and aboveaverage (upper quartile $>75 \%$ ).

We have also performed a subgroup analysis based on gender, right or left-handedness and former recreational activities. The comparison was based on the aforementioned 3 categories. The values of the final biomodel measurements were used.

\section{Statistical analysis}

The Kolmogorov-Smirnov test assessed normality of the data. The ANOVA and the Friedman test were used to assess significant differences in quantitative variables at each of the all follow-up courses. Comparing the time and the quality of suturing Spearman rank correlation, for evaluation the results Wilcoxon-test was used $p<0.05$ was considered as statistically significant.

\section{- Results}

\section{Quantitative assessment}

Compared the results of the measurements at beginning and at the end of the class, both in "Basic Surgical Techniques" and "Surgical Operative Techniques" courses there were a definite improvement in the time required for taking a stitch both on synthetic and on biomodel. As for the basic course, taking stitches on synthetic model took significantly less time ( $p<0.001$ both in the classroom (5th week)) and in the operating room (8th week). The same was experienced in case of biomodels, on the 4th week and on the 14th week of the course, both in the operating room $(p<0.001)$. In case of the elective course there was also a significant development with synthetic models both in the classroom (1st week) $(p<0.001)$ and in the operating room ( $3 r d$ week) $(p=0.003)$ as well as with biomodels on the 2 nd week $(p=0.006)$ and on the 4 th week $(p=0.049)$ in the operating room (Figure 1). 


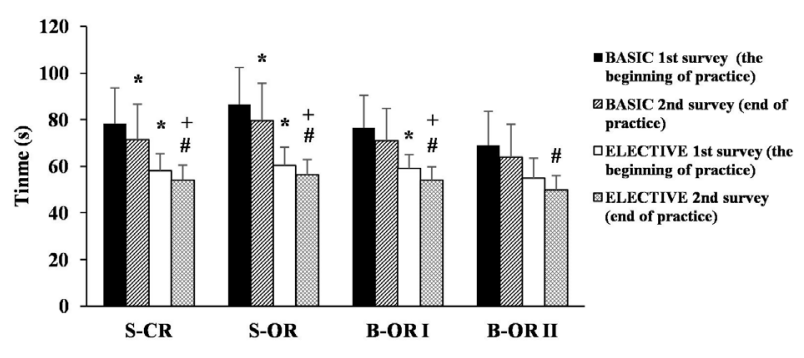

Figure 1 - Time of suturing of the basic and consecutive elective courses comparing the $1^{\text {st }} v s$. $2^{\text {nd }}$ survey. $\left({ }^{*} p<0.05\right.$ vs. BASIC $1^{\text {st }}$ survey; $\# p<0.05$ vs. ELECTIVE $1^{\text {st }}$ survey; $+p<0.05$ vs. BASIC $2^{\text {nd }}$ survey); (S-CR: synthetic model in the classroom; S-OR: synthetic model in the operating room; B-OR: biomodel in the operating room)

Over the length of the course (from $4^{\text {th }}$ to $14^{\text {th }}$ week) in "Basic Surgical Techniques" significant improvement was found $(p<0.001)$, only these values were found when working on biomodels. Depending on the type of the model the view is a bit more complex. With synthetic models (from the 5th week to 8th week) an unexpected, significant increase was found $(p<0.001)$. It should be noted, that the $5^{\text {th }}$ week measurement was carried out in the classroom while the $8^{\text {th }}$ week measurement in the operating room. In "Surgical Operative Techniques" consecutive elective courses the average time of taking stitches decreased significantly from the $1^{\text {st }}$ (on synthetic model) to the $4^{\text {th }}$ week (on biomodel) of the course $(p=0.016)$. Checking the synthetic model only, it was surprising that the average duration mildly increased from the $1^{\text {st }}$ week (in the classroom) to the $3^{\text {rd }}$ week (in the operating room) $(p=0.137)$. On biomodels the time had decreased (from $2^{\text {nd }}$ to the $4^{\text {th }}$ week, both in the operating room $)(p=0.026)$.

Comparing the average time required for the stitch during the basic course and the consecutive elective course, we found significant difference between the similar measurements of the trainings: S-CR basic vs. S-CR elective; S-OR basic vs. S-OR elective; B-OR basic vs. B-OR I elective and B-OR II basic vs. B-OR II elective (in all $\mathrm{p}<0.001$ ) (Figure 2).

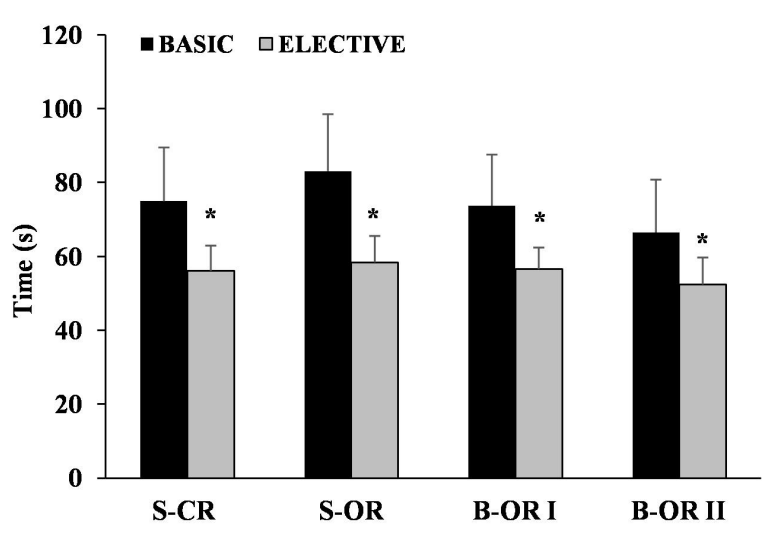

Figure 2 - Time of suturing comparing the basic and consecutive elective courses. $\left({ }^{*} p<0.001\right.$ vs. BASIC); (S-CR: synthetic model in the classroom; S-OR: synthetic model in the operating room; B-OR: biomodel in the operating room)

\section{Qualitative assessment}

According to our score-system during the basic course the average value working on synthetic model in the classroom (S-CR) was 13.6 \pm 1.37 points (max. 20 points) and $16.41 \pm 1.2$ points under operating room circumstances (S-OR), while working on biomodels in the operating room it was $13.12 \pm 1.49$ points in case of the 1 st $(B-O R I)$ and $17.89 \pm 1.43$ points in the 2nd measurements (B-OR II).

The results of the consecutive elective course were: $14.48 \pm 1.21$ points (S-CR), $16.85 \pm 1.4$ points $(S-O R), 13.96 \pm 1.51$ points ( $B$ OR I) and $18.52 \pm 1.36$ points (B-OR II). In the elective course the students got more points than in basic course, but between the courses no significant difference was found.

Working on synthetic model most of the problems were concentrated to the following areas: 1 . the angle of the needle is $90^{\circ}$ to the skin (piercing the skin with the needle at a 900 angle and rotating (supinating) the needle holder when the needle is driven through the tissue); 2. the model pad remains in place during the procedure; 3 . security of the knot 
(not tight, not loose). In case of biomodels the problems were somewhat different: 1. dynamic work (effortless flow from one move to the next); 2. identical distance from the wound edges on both sides; 3 . stitching carried out with a flick of the wrist (Figure 3).

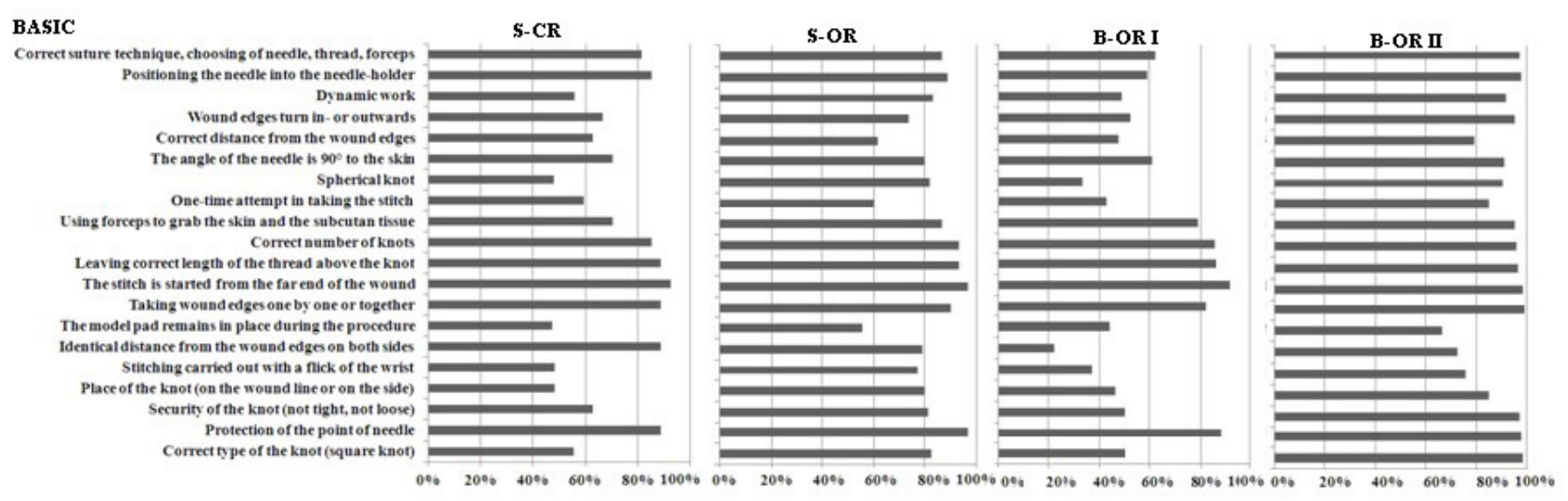

ELECTIVE

Correct suture technique, choosing of needle, thread, forceps Positioning the needle in to the needle-holder Wound edges turn in- or outwards Correct distance from the wound edges The angle of the needle is $90^{\circ}$ to the skin Spherical knot One-time attempt in taking the sitch
tising forceps to grab the skin and the subcutan tissue Correct number of knots The stitch is started from the far end of the wound Taking wound edges one by one or together The model pad remains in place during the procedure Identical distance from the wound edges on both sides Stitching carried out with a nick of the wrist Place of the knot (on the wound line or on the side) Security of the knot (not tight, not loose) Correct type of the knot (square knot)
S-OR

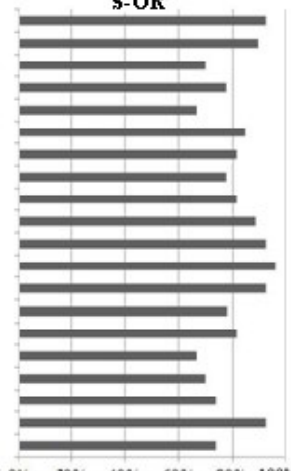

B-OR I

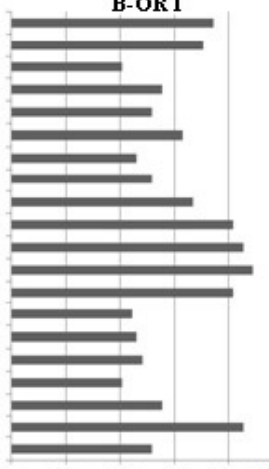

B-OR II

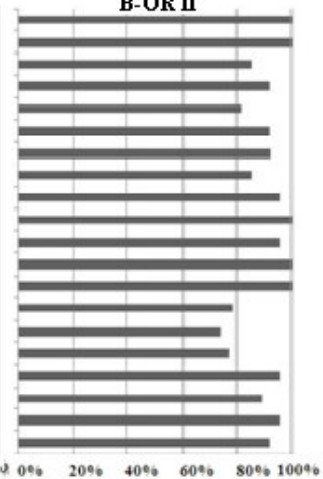

Figure 3 - Qualitative development during the "Basic Surgical Techniques" and "Surgical Operating Techniques" courses Longer lines (approaching 100\%) mean better quality. (S-CR: synthetic model in the classroom; S-OR: synthetic model in the operating room; B-OR: biomodel (porcine foot) in the operating room)

Similar to the duration of the sutures, the quality of work was also poorer when the students worked in the operating room for the first time. In general, the values had an increasing tendency in both courses, although they were far from the maximum, so there had still been room for improvement.

\section{Development expressed in category change}

For further evaluation we created three categories based on the duration of the sutures: below-average (BA), average (A) and above-average (AA) (Table 1 ).

The leap from $B A$ to $A A$ category was 
considered the most remarkable improvement, but also moving from $B A$ to $A$ or from $A$ to $A A$ category was also considered an improvement.

Table 1 - Categories based on the duration of the sutures.

\begin{tabular}{lcccc}
\hline & S-CR & S-OR & B-OR \\
\hline $\begin{array}{l}\text { SUTURE } \\
\text { above-average }\end{array}$ & & & & \\
$>75 \%$ & $<60 \mathrm{~s}$ & $<63,75 \mathrm{~s}$ & $<57 \mathrm{~s}$ \\
average 25-75\% & $60-84$ & $63,75-$ & \\
below-average & $\mathrm{s}$ & $91,5 \mathrm{~s}$ & $57-75 \mathrm{~s}$ \\
$<25 \%$ & $>84 \mathrm{~s}$ & $>91,5 \mathrm{~s}$ & $>75 \mathrm{~s}$ \\
\hline
\end{tabular}

(S-CR: synthetic model in the classroom; S-OR: synthetic model in the operating room; B-OR: biomodel (porcine foot) in the operating room)

All over the curriculum of the basic and the elective course there has been a steady progress. More and more students leapt one or even two categories, which meant that there were more above-average and less belowaverage students among the total number of them. The advance is apparent during each class (from the beginning to the end) and also over the courses.

Analysing the basic course, while there were only 14 (9.21\%) of the total 152 students in the above-average category at the end of the practice in Test 1, to the end of the course (Test 2) it had raised to 59 (38.82\%). The results of the tests with both synthetic and biomodel are summarized in Table 2.

At the end of the elective course, in which each student was interested in surgery, nobody belonged to below-average category and 21 from the total 27 got the above-average qualification (Table 3).

Table 2 - Summary of the scores of the basic course.

\begin{tabular}{|c|c|c|c|c|c|c|c|c|}
\hline \multirow[t]{2}{*}{ BASIC } & \multicolumn{2}{|c|}{$\begin{array}{c}\text { Test } 1 \text { ( } 4^{\text {th }} \text { week) } \\
\text { B-OR I }\end{array}$} & \multicolumn{2}{|c|}{$\begin{array}{c}\text { Test } 2 \text { ( } 5^{\text {th }} \text { week) } \\
\text { S-CR }\end{array}$} & \multicolumn{2}{|c|}{$\begin{array}{c}\text { Test } 3 \text { ( } 8^{\text {th }} \text { week) } \\
\text { S-OR }\end{array}$} & \multicolumn{2}{|c|}{$\begin{array}{c}\text { Test } 4 \text { ( }\left(14^{\text {th }} \text { week) }\right. \\
\text { B-OR II }\end{array}$} \\
\hline & $\begin{array}{c}1 \text { st } \\
\text { survey* }\end{array}$ & $\begin{array}{l}\text { 2nd } \\
\text { survey** }\end{array}$ & $\begin{array}{c}\text { 1st } \\
\text { survey* }\end{array}$ & $\begin{array}{c}\text { 2nd } \\
\text { survey** }\end{array}$ & $\begin{array}{c}1 \text { st } \\
\text { survey* }\end{array}$ & $\begin{array}{c}\text { 2nd } \\
\text { survey** }\end{array}$ & $\begin{array}{c}1 \text { st } \\
\text { survey* }\end{array}$ & $\begin{array}{l}\text { 2nd } \\
\text { survey** }\end{array}$ \\
\hline $\begin{array}{l}\text { above- } \\
\text { average }>75 \%\end{array}$ & $(5 \%)$ & 14 & 6) & 27 & 11 & 29 & $\%)$ & \%) \\
\hline $\begin{array}{l}\text { average } \\
25-75 \%\end{array}$ & 72 (47\%) & $96(63 \%)$ & $96(63 \%)$ & 99 (65\%) & 75 (49\%) & 88 (58\%) & 72 (47\%) & 62 (40\%) \\
\hline $\begin{array}{l}\text { below- } \\
\text { average }<25 \%\end{array}$ & 73 (48\%) & $42(28 \%)$ & $42(28 \%)$ & $26(17 \%)$ & $66(44 \%)$ & $35(23 \%)$ & 43 (29\%) & 31 (20\%) \\
\hline
\end{tabular}

*the beginning of the practice; $* *$ the end of the practice

Table 3 - Summary of the scores of the consecutive elective course.

\begin{tabular}{|c|c|c|c|c|c|c|c|c|}
\hline \multirow[t]{2}{*}{ CONSECUTIVE } & \multicolumn{2}{|c|}{$\begin{array}{c}\text { Test } 1 \text { ( } 1^{\text {st }} \text { week) } \\
\text { B-OR I }\end{array}$} & \multicolumn{2}{|c|}{$\begin{array}{c}\text { Test } 2 \text { ( } 2^{\mathrm{h}} \text { week) } \\
\text { S-CR }\end{array}$} & \multicolumn{2}{|c|}{$\begin{array}{c}\text { Test } 3 \text { ( } 3^{\text {rd }} \text { week) } \\
\text { S-OR }\end{array}$} & \multicolumn{2}{|c|}{$\begin{array}{c}\text { Test } 4 \text { ( } 4^{\text {th }} \text { week) } \\
\text { B-OR II }\end{array}$} \\
\hline & $\begin{array}{c}1 \text { st } \\
\text { survey* }\end{array}$ & $\begin{array}{c}\text { 2nd } \\
\text { survey** }\end{array}$ & $\begin{array}{c}1 \text { st } \\
\text { survey* }\end{array}$ & $\begin{array}{c}\text { 2nd } \\
\text { survey** }\end{array}$ & $\begin{array}{c}1 \text { st } \\
\text { survey* }\end{array}$ & $\begin{array}{c}\text { 2nd } \\
\text { survey** }\end{array}$ & $\begin{array}{c}1 \text { st } \\
\text { survey* }\end{array}$ & $\begin{array}{c}\text { 2nd } \\
\text { survey** }\end{array}$ \\
\hline $\begin{array}{l}\text { above- } \\
\text { average }>75 \%\end{array}$ & $1(3 \%)$ & 14 (52\%) & $2(8 \%)$ & $21(78 \%)$ & $4(15 \%)$ & $17(63 \%)$ & $6(22 \%)$ & $22(81 \%)$ \\
\hline $\begin{array}{l}\text { average } \\
25-75 \%\end{array}$ & 15 (56\%) & $13(48 \%)$ & 16 (59\%) & $6(22 \%)$ & $10(37 \%)$ & $0(0 \%)$ & $18(67 \%)$ & $5(19 \%)$ \\
\hline $\begin{array}{l}\text { below- } \\
\text { average }<25 \%\end{array}$ & $11(41 \%)$ & $0(0 \%)$ & $9(33 \%)$ & $0(0 \%)$ & $13(48 \%)$ & $10(37 \%)$ & 3 (11\%) & $0(0 \%)$ \\
\hline
\end{tabular}

*the beginning of the practice; ${ }^{* *}$ the end of the practice

(S-CR: synthetic model in the classroom; S-OR: synthetic model in the operating room;

B-OR: biomodel (porcine foot) in the operating room) 
Differences based on gender, dominant hand, positive past record and interest in surgery

The distribution of female and male students by average, below-average and above-average categories in "Basic Surgical Techniques" course was as follows: at the and of the course $19(20.21 \%)$ female students belonged to $B A, 38(40.43 \%)$ to $A$ and $37(39.36 \%)$ to AA category (total 94), 11(18.97\%) male students to $B A, 25(43.1 \%)$ to $A$ and $22(37.93 \%)$ to AA (total 58). Compared to the beginning of the course 21 out of $94(22.34 \%)$ female and 11 out of $58(18.97 \%)$ male students showed progress by leaping categories. There was practically no difference in genders.

In case of the elective course there were neither female nor male student in $B A$, $4(25 \%)$ in $A$ and $12(75 \%)$ in AA category out of the 16 female students and $3(27.27 \%)$ in $A$ and $8(72.73 \%)$ out of the 11 male participants. It was very similar to that of the basic course. Altogether 9(56\%) female and 7(64\%) male students showed progress by leaping categories, which is higher rate than that of the basic course and indicates higher proportion of progress in males.

We also wanted to check the difference between right and left-handed students. At the end of the basic course $28(20 \%)$ right-handed students belonged to $\mathrm{BA}, 58(41.43 \%)$ to $\mathrm{A}$ and $54(38.57 \%)$ to $A A$ (total 140 ) while $3(25 \%)$ lefthanded one belonged to $B A, 4(33.33 \%)$ to $A$ and $5(41.67 \%$ ) to $A A$ (total 12 ). So there was no significant difference concerning the dominant hand.

In the elective course neither right (total 22) nor left-handed (total 5) students belonged to BA, $5(22.73 \%)$ right-handed and $1(20 \%)$ lefthanded was in $A$ and $17(77.27 \%)$ right-handed and $4(80 \%)$ left-handed in AA category. There was no significant difference.

Among students who had a specific past record concerning assumed manual skills (playing musical instruments, craftwork: fine arts, handicraft, playing computer games etc.) the distribution was: without such antecedents 24(28.24\%) students belonged to $\mathrm{BA}, 40(47.06 \%)$ to $\mathrm{A}$ and $21(24.70 \%)$ to AA category (total 85$)$. With positive past record it was $7(10.44 \%)$ in $B A, 22(32.84 \%)$ in $A$ and $38(56.72 \%$ ) in AA category (total 67 ), so significantly more students belonged to "above average" category from the students with previous positive record regarding manual skills.

During the consecutive elective course, where all students had a special interest to surgery, $72.2 \%$ of the students developed compared to the basic course. There was no change in $25 \%$ and deterioration was found in $2.8 \%$ of them.

Spearman rank analysis did not show correlation between the time and the quality of suturing. According to the suturing time in the one-way Friedman test comparison statistically significant changes were also observed between the S-CR, S-OR, B-OR I, $\mathrm{B}-\mathrm{OR}$ II at the basic and consecutive courses $(p<0.001)$, respectively.

\section{Discussion}

The need for surgical skill programs during medical education is unquestionable and specifically designed formal curricula are also essential. Our university has a 15-week curriculum called "Basic Surgical Techniques” for undergraduate medical students including lectures and practices. In the past, the teaching of operative surgery followed the concept of "see one, do one, teach one" but it is no longer tenable ${ }^{21}$. The efficiency, effectiveness and ethics of this model all has been increasingly questioned and replaced by a model of competence development.

The undergraduate education also requires approppriate models and simulators for learning and practising the basic surgical 
skills. However, there are several difficulties in finding the ideal model. In the past decade various bench models have been discussed, evaluated and used, such as low-fidelity bench models including synthetic (plastic, rubberized) and organic (fruit, vegetables) types. Highfidelity bench models are also available (chicken skin, ox tongue, cadaveric models, pig feet and pig heads) $)^{22-23}$. However, the choice of a particular model should not be based solely upon its fidelity. Other requirements, such as availability, versatility, reproducibility and costs should also be considered. Several athors have been objectively demonstrated that beginners had been acquired surgical skills on bench models, regardless of model fidelity ${ }^{24}$.

In view of all this we decided to use two different types of bench models: synthetic model and pig feet biomodel. Both are cheap, portable, and easily available and have minimal risk.

To assess the efficacy, objective feedback is also crucial to the structured learning of surgical skills. Valid and reliable assessment of technical skills is needed. Many authors think that feedback produces motivation, supplies reinforcement for correct actions, dissuades incorrect action and can provide information about errors as a basis for correction ${ }^{15}$. Several methods have been applied, for example the Objective Structured Assessment of Technical Skills (OSATS) in which candidates perform a series of standardized surgical tasks on bench models under the supervision of an expert ${ }^{27}$. The examination consists of two components: a task-specific checklist and a non-specific global rating scale. Its reliability and validity was showed by a number of experiments in bench models and in live animal models ${ }^{26-27}$.

In our present study we aimed to evaluate the skills and follow up the development of the students by measuring the time and evaluating the quality of taking simple interrupted stitches. For qualitative evaluation we decided to use the OSATS method, but without the global rating scale only the checklist was applied in a modified form, that was adapted to the training program of our department.

In the time results a definite improvement was seen during one class, during the courses and between the courses, too. The development during one class was undisputed. Over the length of the course similar development was seen, as well as in comparison of the basic and advanced course. The time required for the stitches has been significantly shortened. More and more students belonged to the 'above-average' category. During the elective course the improvement was more remarkable. While over the elective course the number of 'aboveaverage' students raised from 9 to 39\%, over the elective course increased by $70 \%$ reaching $78 \%$.

The unexpected decline in the dynamics of performing the task on plastic model may be explained by the circumstances that changed from the 5 th to the $8^{\text {th }}$ week. The venue for taking stitches was the classroom on the 5th and the operating room on the 8th week. The operating room environment and the relatively new challenge of sharing the attention between the task and the adherence to sterility might have distracted the attention of the students and had resulted in slowing-down of taking stitches.

The checklist score for the quality assessment also showed a good progress during both courses. The movements were more fluent, there were fewer errors, but it was independent from the time results. The quality has improved by time, but no significant improvement was found between the basic and elective course. The problematic steps (knot security, dynamic work etc.) require increased attention during trainings.

Although we have not find any significant difference based on gender or handedness, some recreational activities seemed to improve the dexterity of the students and had a positive impact on their surgical skills. Significantly more students belonged to "above average" 
category in this group. Similar findings were found in case of students having interest in surgery. A significantly greater proportion of students showed an improvement in this group compared to the others.

Like many other authors, we are of the opinion that the key factor for surgical skill improvement is partly in the careful design of the curriculum, in the other hand in an adequate model, where students can utilize the acquired knowledge and skills with lasting effect ${ }^{5,28-31}$. It is also generally considered, that the macro and microsurgical skills should be first mastered in the lab and only then applied in the clinic ${ }^{32}$.

In a study of Liddell et al. ${ }^{33}$ it was also found that 3-hour practical skill training in Year 3 medical students was significantly associated with the students' improvement. A total of $75 \%$ of students in the intervention group inserted a suture satisfactorily compared to $63 \%$ of students in the control group. Although the performance of tying a knot was poorer in both groups, however, a significantly greater proportion of students in the intervention group (62\%) had satisfactorily judged result compared with the control group.

We do believe that all the improvements were due also to the fact, that students got an objective feedback that highlighted the deficiencies, which had made it possible to correct them. In addition, confronting the errors, they would have become more motivated to do a good job.

Objective feedback, valid and reliable assessment is important in teaching surgical skills. Our evaluation "package" proved to be suitable for assessing students' skills, demonstrating the development and detecting the deficiencies. The beneficial effect of consecutive training programs for surgical skill development was obvious. Based on the curriculum of our teaching program, students were able to perform stitches more quickly and with higher quality over time. Students with certain recreational activities showed better results and more dynamic development, as well as the ones who were interested in surgery. However, it was found that the operating theatre environment had been an influencing factor that had caused a mild drop in the student's performance. The results of the survey may help in careful design of future courses and training programs and both directly and indirectly may contribute to higher surgical safety later on in the clinical practice.

\section{- References}

1. MacFie CC, Colville RJ, Reid CA. Back to basics: A new suturing model. Br J Plast Surg. 2004 Sep;57(6):591-92. PMID: 15308415.

2. Aggarwal R, Darzi A. Technical-Skills Training in the 21st Century. N Engl. J Med. 2006 Dec;355(25):2695-96. PMID: 17182997.

3. Altinyazar HC, Hosnuter $M$, Unalacak $M$, Koca R, Babucçu OS. A training model for cutaneous surgery. Dermatol Surg. 2003 Nov;29(11):1122-24. PMID: 14641338.

4. Anastakis DJ, Regehr G, Reznick RK, Cusimano M, Murnaghan J, Brown M, Hutchison C. Assessment of technical skills transfer from the bench training model to the human model. Am J Surg. 1999 Feb;177(2):167-70. PMID: 10204564.

5. de Montbrun SL, MacRae S. Simulation in surgical education. Clin Colon Rectal Surg. 2012 Sep;25(3):156-65. PMID: 23997671.

6. Reznick RK., Regehr G., Macrae H.: Testing technical skill via an innovative "Bench Station" examination. Am J Surg. 1997 Mar;173(3):226-30. PMID: 9124632.

7. Lentz GM, Mandel LS, GoffBA. A six-yearstudy of surgical teaching and skills evaluation for obstetric/gynecologic residents in porcine and inanimate surgical models. Am J Obstet Gynecol. 2005 Dec;193(6):2056-61. PMID: 16325615.

8. Khan MS, Bann SD, Darzi AW, Butler PE. Assessing surgical skill using bench station models. Plast Reconstr Surg. 2007 Sep;120(3):793-800. PMID: 17700133.

9. Denadai R, Saad-Hossne R, Oshiiwa M, Bastos EM. Training on synthetic ethylene- 
vinyl acetate bench model allows novice medical students to acquire suture skills. Acta Cir Bras. 2012 Mar;27(3):271-8. PMID: 22460260.

10.Beard JD, Jolly BC, Newble DI, Thomas WEG, Donnelly J, Southgate LJ. Assessing the technical skills of surgical trainees. Br J Surg. 2005 Jun;92:778-82. PMID: 15810048.

11.Brydges R, Kurahashi A, Brümmer V, Satterthwaite L, Classen R, Dubrowski A. Developing criteria for proficiency-based training of surgical technical skills using simulation: changes in performances as a function of training year. J Am Coll Surg. 2008 Feb;206(2):205-11. PMID: 18222371.

12. House AK, House J. Improving basic surgical skills for final year medical students: the value of a rural weekend. Aust N Z J Surg. 2000 May;70(5):344-7. PMID: 10830596.

13. Moulton CA, Dubrowski A, Macrae $H$, Graham B, Grober E, Reznick RK. Teaching surgical skills: what kind of practice makes perfect? A randomized, controlled trial. Ann Surg. 2006 Sep;244(3):400-9. PMID: 16926566.

14.Qayumi AK, Cheifetz RE, Forward AD, Baird RM, Litherland HK, Koetting SE. Teaching and evaluation of basic surgical techniques: the University of British Columbia experience. J Invest Surg. 1999 Nov-Dec;12(6):341-50. PMID: 10630398.

15.Xeroulis GJ, Park J, Moulton CA, Reznick RK, Leblanc $V$, Dubrowski A. Teaching suturing and knot-tying skills to medical students: a randomized controlled study comparing computer-based video instruction and (concurrent and summary) expert feedback. Surgery. 2007 Apr;141(4):442-9. PMID: 17383520.

16.Furka I, Mikó I. Basic surgical techniques (Mútéttani alapismeretek). Debrecen: Debrecen University Press; 2012.

17.Németh N, Furka I, Mikó I. Educational and research activity of the Department of Operative Techniques and Surgical Research, Institute of Surgery at the Medical and Health Science Center, University of Debrecen in Hungary. Acta Cir Bras. 2013 May;28(5):403-6. PMID: 23702945.
18.Pető K, Németh N, Lesznyák T, Furka I, Mikó I. Main indicators of educational activity of the Department of Operative Techniques and Surgical Research at the University of Debrecen between 2000-2013. Magyar Seb. 2013;66(3):171-6.

19. Mikó I, Furka I. Basic surgical techniques, Faculty of Medicine. 3ed. Debrecen: Debrecen University Press; 2011.

20.Kolozsvari NO, Fieldman LS, Vassiliou MC, Demyttenaere S, Hoover ML. Sim one, do one, teach one: considerations in designing training curricula for surgical simulation. J Surg Educ. 2011 Sep-Oct;68(5):421-7. PMID: 21821224.

21.Denadai R, Saad-Hossne R, Todelo AP, Kirylko L, Souto LR. Low-fidelity bench models for basic surgical skills training during undergraduate medical education. Rev Col Bras Cir. 2014 Mar-Apr;41(2):137-45. PMID: 24918729.

22.Boros M. Skills' training and evaluation. Szeged: Innovariant Kft; 2008.

23.Bauer F, Rommel N, Kreutzer K, Weitz J, Wagenpfeil S, Gulati A, Wolff KD, Kesting MR. A novel approach to teaching surgical skills to medical students using an ex vivo animal training model. J Surg Educ. 2014JulAug;71(4):459-65. PMID: 24776865.

24.Grober ED, Hamstra SJ, Wanzel KR, Reznick RK, Matsumoto ED, Sidhu RS, Jarvi KA. The educational impact of bench model fidelity on the acquisition of technical skill: the use of clinically relevant outcome measures. Ann Surg. 2004 Aug;240(2):374-81. PMID: 15273564.

25. Reznick RK, MacRae H. Teaching surgical skills - Changes in the wind. N Engl J Med. 2006 Dec;355(25):2664-9. PMID: 17182991.

26.Goff BA, Lentz GM, Lee D, Houmard B, Mandel LS. Development of an objective structured assessment of technical skills for obstetric and gynecology residents. Obstet Gynecol. 2000 Jul;96(1):146-50. PMID: 10862857.

27. Martin JA, Regehr G, Reznick R, MacRae $\mathrm{H}$, Murnaghan J, Hutchison C, Brown M. Objective structured assessment of technical skill (OSATS) for surgical residents. Br J Surg. 
1997 Feb;84(2):273-8. PMID: 9052454.

28.Datta V, Mackay S, Mandalia M, Darzi A. The use of electromagnetic motion tracking analysis to objectively measure open surgical skill in the laboratory-based model. J Am Coll Surg. 2001 Nov;193(5):479-85. PMID: 11708503.

29.Gallagher AG, Satava RM, Shorter GD. Measuring surgical skill: a rapidly evolving scientific methodology. Surg Endosc. 2013 May;27(5):1451-5. PMID: 23371021.

30.Paisley AM, Baldwin PJ, Paterson-Brown S. Validity of surgical simulation for the assessment of operative skill. Br J Surg. 2001 Nov;88(11):1525-32. PMID: 11683753.

31.Satava RM. Historical review of surgical simulation - a personal perspective. World J Surg. 2008 Feb;32(2):141-8. PMID: 18097716.

32. Martins PN, Montero EF. Basic microsurgery training: comments and proposal. Acta Cir Bras. 2007 Jan-Feb;22(1):79-81. PMID: 17293955.

33.Liddell JM, Davidson SK, Taub H, Whitecross LE. Evaluation of prodedural skills training in an undergraduate curriculum. Med. Educ. 2002 Nov;36(11):1035-41. PMID: 12406263.

\section{Acknowledgement}

To the technical staff of the Department of Operative Techniques and Surgical Research.

\section{Correspondence:}

Erzsebet Vanyolos

Department of Operative Techniques and Surgical Research

Institute of Surgery, Faculty of Medicine

University of Debrecen

H-4032 Debrecen, Móricz Zs. krt. 22., Hungary

Phone/Fax: +36-52-416-915

vanyolos@med.unideb.hu

Received: Feb 12, 2017

Review: Apr 17, 2017

Accepted: May 18, 2017
Conflict of interest: none

Financial source: none

\footnotetext{
${ }^{1}$ Research performed at Department of Operative Techniques and Surgical Research, Institute of Surgery, Faculty of Medicine, University of Debrecen, Hungary.
} 